JURNAL PANGAN DAN GIZI Vol (No): 18-23, April 2020

ISSN (Online) : 2656-0291

Tersedia online di http://jurnal.unimus.ac.id/index.php/JPDG

\title{
KARAKTERISTIK ORGANOLEPTIK SUP JAGUNG INSTAN YANG DIPERKAYA TEPUNG CANGKANG TELUR BEBEK
}

\section{Organoleptic Characteristics of Instant Corn Soup enriched Duck Eggshell Flour}

\author{
${ }^{1)}$ Fakhrissal Dian Arga Nugroho, ${ }^{2)}$ Siti Aminah, ${ }^{3)}$ Afrilia Arifatul Lael, ${ }^{4)}$ Neneng Indarti \\ Program studi Teknologi Pangan \\ Fakultas Ilmu Keperawatan dan Kesehatan, Universitas Muhammadiyah Semarang \\ ${ }^{1)}$ Fakhri.arga@gmail.com, ${ }^{2)} \underline{\text { sitiaminah@unimus.ac.id }}$
}

\begin{abstract}
Duck eggshell flour which contains a source of calcium which is useful for increasing calcium in the body, eggshell flour as an addition to instant corn soup enriched with duck eggshell flour. This research method is an experimental method using a completely randomized design (CRD) method. Utilization of duck eggshells made in the form of flour as a mixture of food products including instant soup. Ingredients that can be used as instant soup are sweet corn. Instant corn soup has good nutrition and distinctive characteristics. So, instant corn soup can be enriched in its nutritional content (calcium) by adding calcium from duck eggshell flour. The purpose of this research is to find out the Organoleptic characteristics (color, flavour, texture and taste) instant corn soup enriched with duck eggshell flour. This research uses RAL method which consists of 5 treatments, namely the addition of $0 \%, 5 \%, 10 \%, 15 \%$ and $20 \%$ duck eggshell flour which is then analyzed. The results showed instant corn soup enriched with duck eggshell flour had a different effect on the addition of eggshell flour, the sensory properties of the most preferred taste was $5 \%$.
\end{abstract}

Keywords: duck egg shell flour, organoleptic properties, instant corn soup.

\section{PENDAHULUAN}

Produk pangan instan merupakan suatu produk pangan yang disukai masyarakat dalam era modern ini. Keunggulan produk pangan instan yaitu memiliki sifat ready to cook (siap untuk dimasak) maupun ready to eat (siap untuk dimakan ((Jennifer, 2015; Wangi,
2015). Banyak produk pangan instan yang sudah berkembang dikehidupan masyarakat salah satunya sup instan.

Sup instan merupakan produk makanan kering yang terdiri dari sayuran kering, bumbu dan dengan atau tanpa bahan tambahan makanan lainnya yang diizinkan (Badan Litbang 
Pertanian, 2011). Bahan yang dapat digunakan sebagai sup instan yaitu jagung manis. Jagung selain tinggi karbohidrat juga mengandung komponen vitamin cukup lengkap seperti karoten, tiamin, riboflavin, niasin dan vitamin C (Persagi, 2009). Sup jagung instan merupakan sup berbahan dasar jagung dengan tambahan sayuran dan bumbu yang mengalami proses pengeringan kemudian dibubukkan. Rasa yang agak manis dan warna kuning pada jagung akan menambah citarasa pada sup.

Untuk menambah kandungan gizi pada sup jagung, maka ditambahkan kalsium yang terdapat pada cangkang telur bebek. Cangkang telur bebek masih belum dimanfaatkan secara optimal oleh masyarakat karena karakteristik fisik cangkang yang keras, kasar, aromanya amis dan warnanya tidak menarik. Maka, pemanfaatan cangkang telur bebek dibuat dalam bentuk tepung sebagai campuran pada produk pangan. Tepung cangkang telur bebek sebagai sumber kalsium juga mempunyai karakteristik rasa netral, sehingga dapat digunakan untuk pengkayaan kalsium pada produk pangan seperti sup. Oleh karena itu, penelitian ini bertujuan untuk mengetahui pengaruh penambahan tepung cangkang telur bebek terhadap karakteristik organoleptik pada sup jagung instan yang dihasilkan.

\section{BAHAN DAN METODE}

\section{Bahan}

Bahan baku yang digunakan dalam penelitian ini adalah cangkang telur bebek dan jagung. Bahan kimia yang digunakan adalah $\mathrm{CH}_{3} \mathrm{COOH}$, aquades, dan bahan untuk pembuatan sup jagung meliputi kaldu ayam, susu skim, maltodekstrin bawang bombay, seledri, garam, gula jawa, merica dan daun salam.

\section{Metode}

Pembuatan Tepung Cangkang Telur Bebek

Cangkang telur bebek dibersihkan kemudian dilakukan pengecilan ukuran untuk mempermudah proses perendaman. Cangkang telur kemudian direndam menggunakan aquades pada suhu $100^{\circ} \mathrm{C}$ selama 15 menit, air rendaman dibuang. Selanjutnya, cangkang telur di rendam menggunakan $\mathrm{CH}_{3} \mathrm{COOH}$ di dalam water bath pada suhu $60^{\circ} \mathrm{C}$ selama 3 jam dengan perbandingan cangkang : pelarut adalah $1: 2$. Cangkang hasil perendaman didinginkan dan dibersihkan menggunakan aquades. Cangkang telur yang sudah dingin kemudian dipindahkan ke loyang dan dikeringkan menggunakan cabinet dryer pada suhu $50^{\circ} \mathrm{C}$ selama 3 jam. Cangkang kering selanjutnya ditepungkan menggunakan disc mill, kemudian diayak menggunakan ayakan 100 mesh.

\section{Pembuatan Sup Jagung Instan}

Jagung manis yang sudah dipisahkan dari tongkol kemudian diblanching selama 5 menit, dan dihaluskan menggunakan food processor dengan kecepatan rendah. Setelah itu, sebanyak $1 \mathrm{~kg}$ jagung ditambahkan dengan $450 \mathrm{~g}$ kaldu 
ayam alami, $30 \mathrm{~g}$ susu skim, 5\% maltodekstrin dan persentase tepung cangkang telur $(0 \%, 5 \%, 10 \%, 15 \%$, 20\%). Campur bahan tersebut dengan food processor sampai halus \pm 2 menit. Sesudah dari food processor, adonan dicampurkan pada bahan yang sudah ditumis $(30 \mathrm{~g}$ bawang bombay dan $10 \mathrm{~g}$ seledri, $7 \mathrm{~g}$ garam, $30 \mathrm{~g}$ gula jawa, $0,5 \mathrm{~g}$ merica dan $5 \mathrm{~g}$ daun salam) masak hingga mendidih selama 4 menit. Kemudian, langsung masukan drum dyer lalu dikeringkan. Setelah kering, hancurkan kembali dengan food processor dan diayak 80 mesh.

\section{Analisis Karakteristik Organoleptik}

Pengujian organoleptik meliputi uji mutu hedonik dan uji skoring yang meliputi : Warna, tekstur, aroma dan rasa. Uji organoleptik masing - masing parameter menggunakan skala hedonik yaitu : 1 = Sangat tidak suka, $2=$ Tidak suka, $3=$ Agak suka, $4=$ Suka, 5 = Sangat suka. Hasil uji skala hedonik diubah menjadi skala skoring dengan angka sesuai spesifik bahan yang akan diuji, kemudian digunakan untuk analisis secara statistik.

\section{HASIL DAN PEMBAHASAN}

\section{Warna}

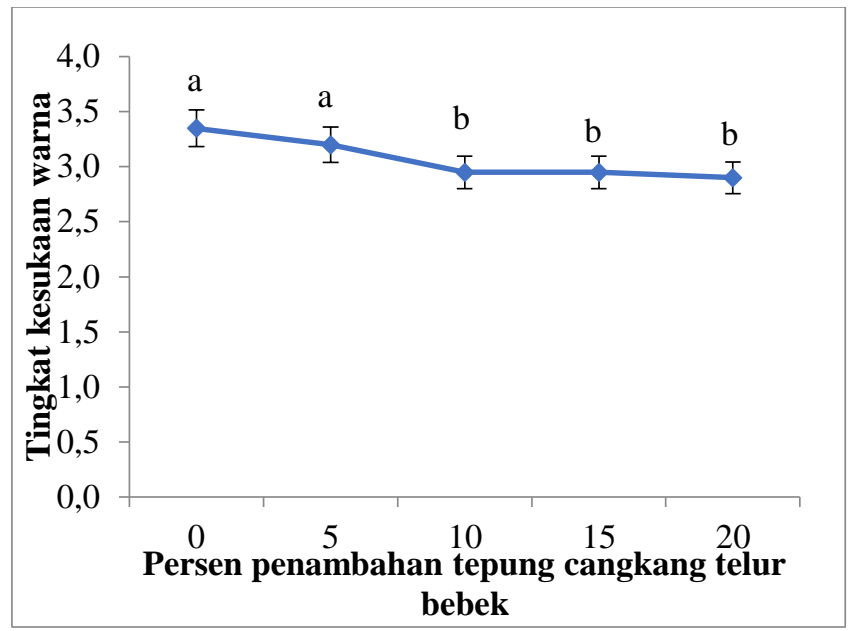

Gambar 1. Nilai organoleptik warna sup jagung instan dengan penambahan tepung cangkang telur bebek

Gambar 1 menunjukkan ada perbedaan tingkat kesukaan panelis terhadap parameter warna sup labu jagung instan dengan penambahan tepung cangkang telur bebek ( $p$ value < 0,05). Semakin tinggi penambahan tepung cangkang, tingkat kesukaan panelis terhadap warna sup cenderung menurun. Penambahan tepung cangkang telur optimal terhadap parameter warna adalah $5 \%(3,20)$, dimana tidak ada beda dengan sup kontrol $(3,35)$ dan berbeda dengan perlakuan lainnya. Hal ini disebabkan karena semakin banyak penambahan tepung cangkang telur bebek pada sup jagung maka warna sup cenderung lebih pucat. Menurut yonata (2017), warna pucat tersebut disebabkan oleh pigmen biliverdin pada cangkang sehingga warna cangkang telur bebek berubah menjadi biru keputihan. Perubahan yang terjadi dikarenakan adanya proses deposisi pigmen biliverdin pada cangkang sehingga selama proses perendaman, 
warna cangkang telur bebek akan mudah terdegradasi menjadi lebih cerah keputihan (Mushawwir dan Latipuddin, 2013). Oleh karena itu, semakin banyak tepung cangkang telur bebek yang ditambahkan pada sup jagung instan maka akan mempengaruhi warna sup jagung.

\section{Aroma}

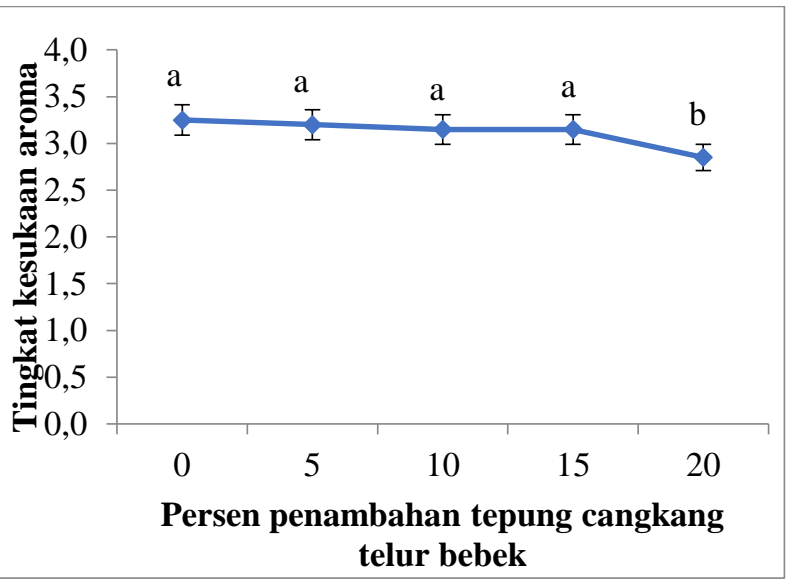

Gambar 2. Nilai organoleptik aroma sup jagung instan dengan penambahan tepung cangkang telur bebek

Gambar 2 menunjukkan ada perbedaan tingkat kesukaan panelis terhadap parameter aroma sup labu jagung instan dengan penambahan tepung cangkang telur bebek ( $p$-value $<0,05)$. Semakin tinggi penambahan tepung cangkang telur bebek, tingkat kesukaan panelis terhadap aroma sup cenderung stabil. Penambahan tepung cangkang telur bebek hingga 15\% tidak mempengaruhi tingkat kesukaan panelis terhadap parameter aroma sup jagung instan.

a. Tekstur

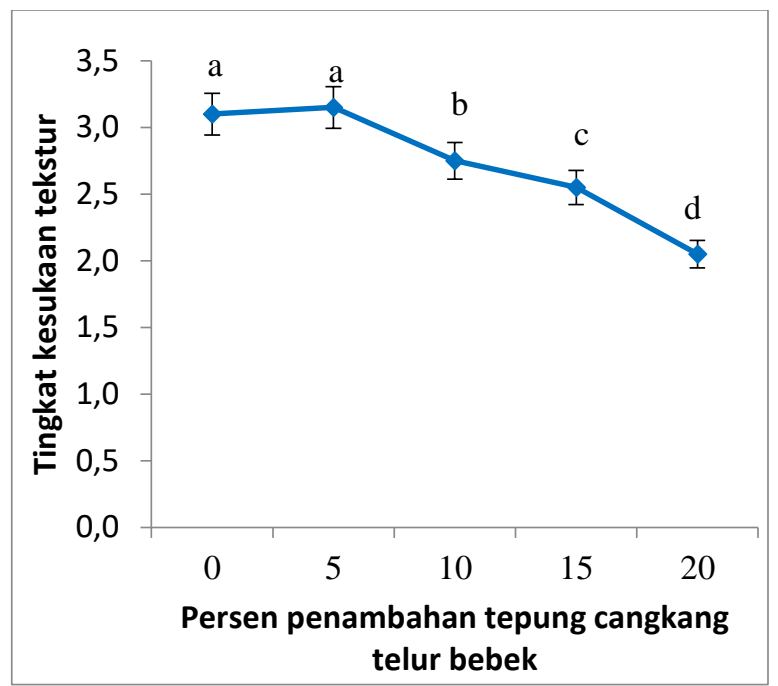

Gambar 3. Nilai organoleptik tekstur sup jagung instan dengan penambahan tepung cangkang telur bebek

Gambar 3 menunjukkan ada perbedaan tingkat kesukaan panelis terhadap parameter tekstur sup jagung instan dengan penambahan tepung cangkang telur bebek ( $p$ value < 0,05). Semakin tinggi penambahan tepung cangkang, tingkat kesukaan panelis terhadap tekstur sup cenderung menurun. Penambahan tepung cangkang telur optimal terhadap parameter tesktur adalah $5 \%(3,15)$, dimana tidak ada beda dengan sup control $(3,10)$ dan berbeda dengan perlakuan lainnya. Semakin tinggi penambahan pada sup semakin kasar teksturnya karena pengaruh penambahan tepung cangkang telur bebek yang seperti pasir.

\section{Rasa}




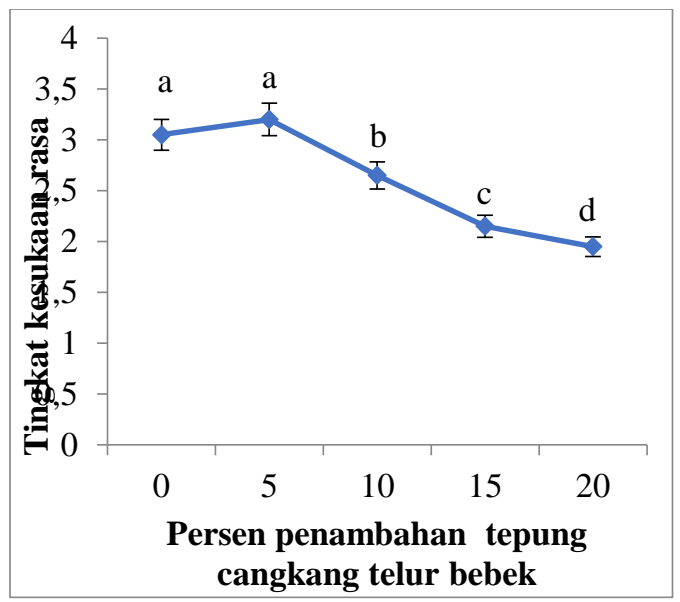

Gambar 4. Nilai organoleptik rasa sup jagung instan dengan penambahan tepung cangkang telur bebek

Gambar 4 menunjukkan ada perbedaan tingkat kesukaan panelis terhadap parameter rasa sup jagung instan dengan penambahan tepung cangkang telur bebek ( $p$-value < $0,05)$. Semakin tinggi penambahan tepung cangkang, tingkat kesukaan panelis terhadap tekstur sup cenderung menurun. Penambahan tepung cangkang telur optimal terhadap parameter tesktur adalah 5 $\%$ (3,20), dimana tidak ada beda dengan sup control $(3,05)$ dan berbeda dengan perlakuan lainnya.

\section{KESIMPULAN}

Sup jagung instan mempunyai karakteristik Penambahan tepung cangkang telur bebek berpengaruh terhadap karakteristik organoleptik (warna, aroma, tekstur dan rasa). Penambahan tepung cangkang telur bebek yang paling disukai panelis yaitu sebesar 5\% dengan nilai ratarata warna 3,20; aroma 3,20; tekstur 3,15 ; dan rasa 3,20 .

\section{UCAPAN TERIMAKASIH}

Penulis mengucapkan terima kasih kepada Kementerian Riset, Teknologi, Dan Pendidikan Tinggi Republik Indonesia yang telah memberikan dana untuk penelitian kreativitas mahasiswa tahun anggaran 2019

\section{DAFTAR PUSTAKA}

Andi Mushawwir dan D, Latipudin. 2013. Biologi Sintetis Telur : Perspektif Fisiologi, Biokimia dan Molekular Produksi Telur. Edisi Pertama. Graha Ilmu, Yogyakarta. 94-96.

Badan Libang Pertanian. 2011. Potensi Sup Instan sebagai Alternatif Pangan Darurat. Edisi 16-22 No.3431 Tahun XLII.

Fatdhilah, N., dan Anna, N. 2014.Pengaruh Jumlah Maltodekstrin dan Lama Pengeringan terhadap Sifat Organoleptik Sup Labu Kuning Instan. E-jurnal Boga, Vol 3 Hal 7685 .

Jennifer. 2015. Pemanfaatan Pati Ubi Jalar (Ipomoea Batatas) Terfermentasi dalam Produk Sup Krim Instan. Skripsi. IPB, Bogor

Kartikasari, O. 2006. Aplikasi Tepung Kacang Merah (Phaseolus Vulgaris) dalam Pembuatan Sup Kacang Merah Instan: Evaluasi fisik, kimia, dan sensoris. Skripsi. UNIKA, Semarang. 
Persagi, 2009. Tabel Komposisi Pangan Indonesia. Jakarta

Rahayu. 2001. Penuntun Praktikum Penilaian Organoleptik. Bogor: Fakultas Teknologi Pertanian, Institut Pertanian Bogor.

Wangi, M. P. 2015. Pemanfaatan Pati Sagu (Metroxylon Sagu) dan Koro Pedang (Canavalia Ensiformis) dalam Produk Sup Krim Instan. Skripsi. IPB.

Yonata, D. 2017. Kadar Kalsium Dan Karakteristik Fisik Tepung Cangkang Telur Unggas dengan Perendaman Berbagai Pelarut.Skripsi. Universitas Muhammadiyah Semarang, Semarang

Yonata, D., Siti A., Wifaayatul A., Afrilia A.L., dan Anita R. R. 2017. Physical and Organoleptic Characteristics of Poultry Eggshell Powder Extracted with $\mathrm{CH}_{3} \mathrm{COOH}$ and $\mathrm{NaOH}$. Prosiding Seminar ISET $3^{\text {rd }}$. Universitas Muhammadiyah Semarang, Semarang 